\title{
International differences in the evaluation of conditions for newborn bloodspot screening: a review of scientific literature and policy documents
}

\author{
Marleen E Jansen ${ }^{\star 1,2}$, Selina C Metternick-Jones ${ }^{3}$ and Karla J Lister ${ }^{3}$ \\ Despite international adoption of newborn bloodspot screening (DBS), no two countries' screening programs are the same. This \\ article aims to understand what factors influence DBS decision-making criteria and how conditions are assessed against them. \\ In doing so, it offers unique insights into the international landscape of DBS. A systematic review on DBS criteria in scientific \\ literature was first undertaken. Through this, five topics were identified for consideration when analyzing DBS decision-making. \\ Using these five topics as a template, a side-by-side comparison was conducted on DBS in policy documents of eight countries. \\ Programs are using different approaches to explore the same policy issues, including: the beneficiary of DBS, definition of \\ criteria, the way conditions are assessed, level of evidence required, and recommendations after assessment. These differences \\ have the potential to result in increased disparity across DBS internationally. Ultimately, governments need to decide on their \\ role and develop an approach to DBS decision-making in line with this role. The analyses presented in this article highlight that \\ despite programs' commonalities, no one 'DBS decision-making solution' exists. Understanding the different approaches to \\ decision-making within the literature and policy settings, provides an objective starting point for structured decision-making \\ approaches for DBS programs.
}

European Journal of Human Genetics (2017) 25, 10-16; doi:10.1038/ejhg.2016.126; published online 16 November 2016

\section{INTRODUCTION}

Internationally, screening is recognized as an important population health initiative. ${ }^{1,2}$ Screening involves the systematic testing of an asymptomatic population for a specific condition. ${ }^{3,4}$ Its goal is to identify individuals who are at an increased risk of developing a condition, or who are in the early stages of a disease., ${ }^{5,6}$ These individuals are then eligible for early intervention, with the aim of reducing morbidity and mortality. 1,5 In addition to these individual benefits, screening also aims to minimize the negative societal and economic impacts of life threatening diseases. ${ }^{3,47}$ To maximize the health and wellbeing of a population through screening, governments worldwide implement screening programs for a range of conditions. ${ }^{8}$

Although screening can have many benefits, it can also result in harm. ${ }^{9-11}$ These harms might be physical, from testing or treatment, or psychological, relating to anxiety due to receiving a false positive test result. ${ }^{12,13}$ Therefore, careful and transparent decision-making is needed to ensure that the benefits of screening always outweigh the harms. ${ }^{1,11,12,14-18}$ To maximize the benefits and minimize harms, policy makers use decision-making criteria. ${ }^{1,7}$ These criteria provide a framework against which conditions can be assessed for their suitability for screening. $5,17,19,20$ The population screening principles formulated by Wilson and Jungner (Box 1) ${ }^{21}$ are considered to be the gold standard for assessing conditions for screening. However, they are not regarded as adequate for all screening programs, including for newborn bloodspot screening (DBS).,14,22-24 Instead, they are regarded as a starting point on which to build tailored criteria. $^{10,22,25}$

DBS is one of the longest running screening initiatives in the world. ${ }^{19,22,26}$ It screens newborns within the first days of life for multiple conditions. ${ }^{8,9}$ The conditions screened are often rare and need life-long treatment or management. This makes them difficult to assess against traditional decision-making criteria originating from the Wilson and Jungner principles. When assessing conditions against the criteria, adhering to current standard of evidence-based policy making poses a challenge. ${ }^{27-29}$ Although evidence from randomized controlled trials (RCTs) is considered the gold standard on which to base decisions, it is scarce for rare conditions. In addition, the multiplex technologies currently used in DBS, and the emergence of genomic technologies, mean it is possible to screen for an increasing number of conditions. 1,7,29-32 This further challenges the existing decisionmaking criteria, which focus on assessing one condition at a time. ${ }^{20,33}$ In response to this, many countries and local jurisdictions have translated the traditional screening principles into more detailed criteria, to suit both DBS and their local needs. ${ }^{19,22,24,25,27}$ As a consequence, countries and regions assess conditions for inclusion in their DBS programs differently, resulting in different conditions being included in DBS programs. $8,10,20,23,34$

In this study, we aim to explore what factors influence decisionmaking criteria in DBS and how conditions are assessed against them

${ }^{1}$ Department of Clinical Genetics, Section Community Genetics and EMGO Institute for Health and Care Research, VU University Medical Center, Amsterdam, The Netherlands; ${ }^{2}$ Department of Genetics and Cell Biology, Institute for Public Health Genomics, School for Oncology and Developmental Biology (GROW), Faculty of Health, Medicine and Life Sciences, Maastricht University, Maastricht, The Netherlands; ${ }^{3}$ Screening Policy Section, Office of Population Health Genomics, Department of Health, Government of Western Australia, Perth, Australia

${ }^{*}$ Correspondence: Dr ME Jansen, EMGO+ Community Genetics and Public Health Genomics, PO Box 7057, BS7/A509, 1007 MB Amsterdam, The Netherlands. Tel: +31 0 20 444 8914; Fax: +31 020444 8665; E-mail: m.jansen5@vumc.nl

Received 21 April 2016; revised 16 August 2016; accepted 24 August 2016; published online 16 November 2016 


\section{Box 1 The principles as formulated by Wilson and Jungner ${ }^{21}$}

1. The condition sought should be an important health problem.

2. There should be an accepted treatment for patients with recognized disease.

3. Facilities for diagnosis and treatment should be available.

4. There should be a recognizable latent or early symptomatic stage.

5. There should be a suitable test or examination.

6. The test should be acceptable to the population.

7. The natural history of the condition, including development from latent to declared disease, should be adequately understood.

8. There should be an agreed policy on whom to treat as patients.

9. The cost of case finding (including diagnosis and treatment of patients diagnosed) should be economically balanced in relation to possible expenditure on medical care as a whole.

10. Case finding should be a continuing process and not a 'once and for all' project.

Table 1 Template to facilitate side-by-side comparison of the countries included in the review

\begin{tabular}{ll}
\hline Topic & Description \\
\hline Screening beneficiaries & Who stands to benefit the most from providing NBS for a condition. \\
Definition of criteria & Questions or statements against which evidence is assessed, to consider the appropriateness of screening a condition. \\
Condition assessment & The way the evidence and information are synthesized and used to evaluate conditions. \\
Level of evidence required & Summary of the type of evidence accepted to support the applied score, such as a systematic review, RCT, and/or expert opinion. \\
Recommendation & The outcome of assessing a condition against the decision-making criteria, such as a recommendation for or against screening. \\
\hline
\end{tabular}

across the globe. The focus is on DBS and the unique considerations needed to be made in this multi-disease screening program. Therefore, other forms of newborn screening, including hearing and hip dysplasia, are outside the scope of this study. The exploration of factors influencing decision-making for DBS is achieved through a systematic review of scientific literature, and a review of relevant policy documents in countries with long standing DBS programs: Australia, Canada, Denmark, Germany, the Netherlands, New Zealand, the United Kingdom (UK), and the United States of America (USA). In doing so, this review provides an evidence-based template of topics that should be considered when translating the Wilson and Jungner screening principles into localized decision-making. In line with this, the findings of this study provide essential information and a starting point for those countries, which are currently in the process of developing or revising their decision-making processes. This includes both developed nations with established screening, as well as other countries where DBS programs are either being developed or yet to be established.

\section{METHODS}

To explore factors that influence DBS decision-making criteria and how conditions are assessed against them, this study followed a two-phased search strategy. The first phase involved a systematic review of scientific literature, and the second focused on relevant international policy documents. The aim of the first phase of the study was to identify high level topics that authors recommended should be considered when revising decision-making for DBS. These topics were then used to develop the template presented in Table 1 to analyze the policy documents and enable a side-by-side comparison between countries. These countries include a mix of national and state-based programs, with a different number of conditions screened from 9 to over $30 .^{8}$

\section{Scientific literature}

In the first phase, MJ, SMJ, and KL searched and reviewed articles from PubMed and Web of Science. The key search terms 'newborn screening' and 'criteria' were used. These terms were combined with 'decision-making', 'assessment or evaluation', 'definition', 'expanding', 'removing', 'translation', 'Wilson and Jungner', 'framework', 'policy', and 'implementation'. The search terms were selected based on terminology used in DBS literature and knowledge of the research team. Only articles in English were included, and the resultant literature database was checked for duplicates. Articles relating to other types of newborn screening were excluded, because the aim of this study was to explore the evaluation process specific to DBS programs. Relevant articles were selected based on their title and abstract, and then read in full. Uncertainties about the relevance of an article for the final review were discussed among the team until consensus was reached.

Once articles were identified as being appropriate for final review, they were analyzed for information regarding DBS decision-making. The research team followed an iterative process, whereby they met on multiple occasions to identify common themes and content within the articles. Through this process of selection and refinement, five high level topics were identified as being present within the scientific literature (Table 1). These five topics then were used to develop a template for analyzing the information within the policy documents in the second phase.

\section{Policy documents}

The second phase of the study focused on policy documents in various countries, to identify DBS criteria and how conditions are assessed against them internationally. To identify current relevant policy documents, MJ, SMJ, and KL searched Google and government websites, and contacted stakeholders. This resulted in 26 policy documents from across the globe. Policy documents were included only if: there was clear information on DBS decision-making; and if they were in Dutch, English or German. This resulted in eight countries' policy documents being included in the study: Australia, Canada, Denmark, Germany, Netherlands, New Zealand, UK, and USA. The DBS policies from these countries were assessed against the five topics in the template developed in the 
first phase (Table 1). Using this template, the information on the topics was compared, contrasted, and consideration given to the translation into current DBS policy.

\section{RESULTS}

The following information highlights similarities and differences in factors that influence decision-making criteria in DBS and how conditions are assessed against the criteria. Five high levels topics are discussed here, including: (1) screening beneficiary, (2) definition of criteria, (3) condition assessment, (4) level of evidence required, and (5) recommendation. Although DBS is often synonymous with policy and academic debates on informed consent, financial structure and privacy issues, the review of literature did not identify these as being fundamental concepts influencing decision-making. ${ }^{23,35}$
Therefore, these concepts are not explored within this study. The key high level topics elicited from the review are discussed below and in Table 1. The information here focuses firstly on the scientific review and then provides results of the policy documents.

\section{Scientific articles}

Screening beneficiaries. 'Screening beneficiaries' refers to an individual or group of people who will benefit most as a result of screening for a condition. Beneficiaries could be the child, the family and/or society. ${ }^{1,14,22,24,31,34,36-39}$ The child is the beneficiary if the purpose is to support early clinical intervention and enhance the health outcomes for the newborn. ${ }^{34}$ The family is the beneficiary if the purpose of screening extends to: reducing a diagnostic odyssey;

Table 2 Summary of the policy documents included in the review

\begin{tabular}{|c|c|c|c|c|c|c|c|c|}
\hline \multirow[b]{2}{*}{ Country (jurisdiction) } & \multicolumn{5}{|c|}{ Topics in template } & \multicolumn{3}{|c|}{ Background information } \\
\hline & $\begin{array}{l}\text { Screening } \\
\text { beneficiary }\end{array}$ & Definition of criteria & $\begin{array}{c}\text { Condition } \\
\text { assessment }\end{array}$ & $\begin{array}{c}\text { Level of evidence } \\
\text { required }\end{array}$ & $\begin{array}{l}\text { Recommendation } \\
\text { for screening }\end{array}$ & $\begin{array}{c}\text { Year of publication } \\
\text { or revision }\end{array}$ & $\begin{array}{c}\text { Currently applied to } \\
\text { NBS program }\end{array}$ & $\begin{array}{l}\text { Program } \\
\text { structure }\end{array}$ \\
\hline Australia & $\begin{array}{l}\text { 1. Child } \\
\text { 2. Family }\end{array}$ & $\begin{array}{l}\text { On the basis of W\&J, } \\
\text { with specific amend- } \\
\text { ments and additions } \\
\text { relevant to DBS }\end{array}$ & $\begin{array}{l}\text { Consensus- } \\
\text { based process }\end{array}$ & Rate evidence ${ }^{\mathrm{b}}$ & Categories $^{\mathrm{C}}$ & $\begin{array}{l}2008^{\text {[ref. 3] }} \\
2011^{\text {[ref. 48] }}\end{array}$ & No & $\begin{array}{l}\text { State- } \\
\text { based }^{\text {d }}\end{array}$ \\
\hline Canada (Ontario) & Child only & $\begin{array}{l}\text { On the basis of W\&J, } \\
\text { with specific amend- } \\
\text { ments and additions } \\
\text { relevant to DBS }\end{array}$ & $\begin{array}{l}\text { Consensus- } \\
\text { based process }\end{array}$ & HTA model ${ }^{e}$ & Dichotomous $^{f}$ & $\begin{array}{l}2011^{\text {[ref. 61] }} \\
2015^{\text {[ref. } 51]}\end{array}$ & No & $\begin{array}{l}\text { State- } \\
\text { based }^{\text {d }}\end{array}$ \\
\hline Canada (Quebec) & $\begin{array}{l}\text { 1. Child } \\
\text { 2. Family }\end{array}$ & $\begin{array}{l}\text { On the basis of W\&J, } \\
\text { with specific amend- } \\
\text { ments and additions } \\
\text { relevant to DBS }\end{array}$ & $\begin{array}{l}\text { Consensus- } \\
\text { based process }\end{array}$ & HTA model ${ }^{\mathrm{e}}$ & Categories $^{c}$ & $\begin{array}{l}2007 \text { [ref. 53] } \\
2008 \text { [ref. 60] }\end{array}$ & No & $\begin{array}{l}\text { State- } \\
\text { based }^{\text {d }}\end{array}$ \\
\hline Denmark & $\begin{array}{l}\text { 1. Child } \\
\text { 2. Family }\end{array}$ & $\begin{array}{l}\text { On the basis of W\&J, } \\
\text { summarized to six cri- } \\
\text { teria relevant to DBS }\end{array}$ & $\begin{array}{l}\text { Quantitative } \\
\text { scoring matrix }\end{array}$ & HTA model ${ }^{\mathrm{e}}$ & Dichotomous $^{f}$ & $\begin{array}{l}2007 \text { [ref. 57] } \\
2012 \text { [ref. 50] }\end{array}$ & Yes & National \\
\hline Germany & Child only & $\begin{array}{l}\text { On the basis of W\&J, } \\
\text { with specific amend- } \\
\text { ments and additions } \\
\text { relevant to DBS }\end{array}$ & $\begin{array}{l}\text { Consensus- } \\
\text { based process }\end{array}$ & RCT levelg & Dichotomous $^{f}$ & $\begin{array}{l}2007 \text { [ref. 54] } \\
2011 \text { [refs 55,64] } \\
2014 \text { [ref. 63] } \\
2015 \text { [ref. 62] }\end{array}$ & Yes & $\begin{array}{l}\text { State- } \\
\text { based }^{d}\end{array}$ \\
\hline Netherlands & $\begin{array}{l}\text { 1. Child } \\
\text { 2. Family }\end{array}$ & $\begin{array}{l}\text { On the basis of W\&J, } \\
\text { with specific amend- } \\
\text { ments and additions } \\
\text { relevant to DBS }\end{array}$ & $\begin{array}{l}\text { Consensus- } \\
\text { based process }\end{array}$ & HTA modele & Categories $^{\mathrm{C}}$ & $\begin{array}{l}2005^{\text {[ref. 56] }} \\
2008^{\text {[ref. } 4]} \\
2015^{\text {[ref. } 52]}\end{array}$ & Yes & National \\
\hline New Zealand & $\begin{array}{l}\text { 1. Child } \\
\text { 2. Family }\end{array}$ & $\begin{array}{l}\text { On the basis of W\&J, } \\
\text { with specific amend- } \\
\text { ments and additions } \\
\text { relevant to DBS }\end{array}$ & $\begin{array}{l}\text { Consensus- } \\
\text { based process }\end{array}$ & Rate evidence ${ }^{b}$ & Categories $^{\mathrm{C}}$ & $2011^{\text {[ref. 49] }}$ & Yes & National \\
\hline United Kingdom & Child only & $\begin{array}{l}\text { On the basis of W\&J, } \\
\text { with specific amend- } \\
\text { ments and additions } \\
\text { relevant to DBS }\end{array}$ & $\begin{array}{l}\text { Consensus- } \\
\text { based process }\end{array}$ & RCT levelg & Categories $^{c}$ & $2015_{\text {[refs 58,59] }}$ & Yes & National \\
\hline $\begin{array}{l}\text { United States of } \\
\text { America }\end{array}$ & $\begin{array}{l}\text { 1. Child } \\
\text { 2. Family }\end{array}$ & $\begin{array}{l}\text { On the basis of W\&J, } \\
\text { with specific amend- } \\
\text { ments and additions } \\
\text { relevant to DBS }\end{array}$ & $\begin{array}{l}\text { Quantitative } \\
\text { scoring matrix }\end{array}$ & Rate evidence ${ }^{b}$ & Categories $^{\mathrm{C}}$ & $\begin{array}{l}2006^{\text {[ref. 46] }} \\
2014^{\text {[ref. } 41]} \\
2015^{\text {[ref. } 47]}\end{array}$ & Yes & $\begin{array}{l}\text { State- } \\
\text { based }^{d}\end{array}$ \\
\hline
\end{tabular}

This table provides an overview of the relevant countries' policy documents, against the topic areas identified in the scientific review. It also provides relevant background information, relating to the policies and the programs' structures.

policies and the programs' structures.
a'Review of evidence against each criterion deliberated within an expert panel.

aReview of evidence against each criterion deliberated within an expert panel.
bate high to low, for example 1. systematic review/RCTs, 2. high quality case-control/cohort, 3. well conducted case-control, 4. case reports/expert opinion, 5. No evidence.

${ }^{c}$ Categories ranging from recommended to not recommended, such as 1. suitable, 2. pilot study, 3. not suitable.

dincludes provincial programs.

eHealth technology assessment taking different types of evidence into consideration, but no scoring method reported in reviewed policy documents.

${ }^{f}$ Either for or against screening.

gRCTs considered gold standard and other evidence generally as insufficient. 
supporting the family to prepare for the onset of symptoms of a disease; or supporting future reproductive planning. ${ }^{1,14,24,37,38}$ Society could be considered the beneficiary if: disease burden is reduced, hence decreasing costs for health care and increasing the chance of a productive member contributing to society; and when knowledge about rare diseases is improved. ${ }^{31,39}$ Some authors recommend criteria that focus on families as the beneficiaries of screening. ${ }^{1,14,24,37}$ However, in other literature it is stated that the direct medical benefits to the child must always come first within DBS programs, before considering family benefits. ${ }^{34}$ Hence, this reflects a controversy on the concept of beneficiary, and that there is no consensus on the need for a possible shift in the definition of benefits.

Definition of criteria. The 'definition of criteria' refers to those questions or statements against which evidence is assessed, to consider the appropriateness of screening a condition. In literature it was highlighted that a range of different criteria are used to assess conditions, $, 9,15,20,22-25,29,30,32,34,40-42$ which vary in their level of detail. ${ }^{15,40}$ Most authors built on the principles of Wilson and Jungner, and translated the principles in to more detailed criteria. The primary driver behind this translation appeared to be the need to define more detailed criteria to: make them more relevant to DBS; enable consideration of relevant technologies; and/or to support exploration of the ethical implications for DBS screening. ${ }^{11,18,20,22-25,29,32,34,41-44}$

Condition assessment. 'Condition assessment' relates to the way the evidence and information is synthesized and used to consider the condition. In general a detailed description of the relevant evidence could be used to assess the criteria. ${ }^{32}$ Information was usually synthesized through summarizing relevant studies, sometimes combined with expert opinions, and weighing this evidence against each criterion. ${ }^{11,29,30,32,41,44}$ Alternatively, in the articles stepping through American College of Medical Genetics' (ACMG) approach to decisionmaking, which guided the recommended universal screening panel (RUSP) recommendation in 2006, a condition was assessed against each criterion using numerical scores. ${ }^{9,19,25,36,42}$

Level of evidence. 'Level of evidence' refers to the types of information, which might be used for assessment, such as clinical studies or systematic reviews. Within screening policy, RCTs are considered the gold standard for evidence to arrive at an evidence-based decision. ${ }^{12,24}$ However, the requirement for this level of evidence is challenged in the context of DBS. DBS screens for rare diseases, for which RCTs are often not possible due to limited numbers of individuals with a condition. ${ }^{14,24,27,45}$ Given this, many authors recommend that alternative evidence should be used in the face of rare diseases and a scarcity of RCTs. ${ }^{12,14,15,24,25,28,41,42}$ These alternatives include expert opinions, or conducting a systematic review of current evidence sometimes combined with a decision analytic model. Furthermore, information is needed on ethical, legal, and societal implications, which could be studied using health technology assessment frameworks. ${ }^{18,45}$

Recommendation. 'Recommendation' refers to the outcome of assessing a condition against the decision-making criteria, such as a recommendation for or against screening. The format of these recommendations regarding whether to commence screening for a condition varied from a binary outcome (yes/no), to an extensive ranking or categorical outcome, with up to eight categories. $9,13,15,29,43$ Thus, in the reviewed literature it is highlighted that there are numerous ways of formulating and presenting recommendations.

\section{Policy Documents}

Characteristics of the reviewed policy documents are summarized for each country in Table 2. The similarities and differences in policy approaches shown in Table 2 are further explored in the following.

Screening beneficiary. In the policy documents, all countries focused on the newborn as the primary beneficiary. This aligns with the traditional aim of DBS, which is to prevent serious implications for the newborn by offering timely treatment and management for early onset childhood conditions. ${ }^{3,46-50}$ Policy documents from Ontario mention that there must be reasonable certainty that important clinical benefits for the child will come from screening. ${ }^{51}$ In addition, recently released Dutch guidelines also focus on supporting clinical intervention(s) for the child: 'There must be substantial health gains, achieved through early intervention in severe diseases with a known natural course'. ${ }^{52}$ Although some countries consider family benefits, such as preventing a diagnostic odyssey, they are always considered secondary to direct medical benefit to the child. ${ }^{41}$ Australia and New Zealand explore family benefit within their decision-making. For example, the New Zealand policy highlights that 'In some disorders a benefit for the family may be important, where the condition is untreatable and may lead to early mortality, but where a definitive diagnosis might be aided by the performance of the screening test'. ${ }^{49}$ In policy documents from Québec the clinical utility for 'patients and their families' justifies DBS. ${ }^{48,49,53}$

Definition of criteria. Similar to the academic literature, differences existed in the criteria expressed in the policy documents. One key difference in the policy documents was the amount of detail used to describe the criteria. The questions or statements against which evidence is assessed for each country or jurisdiction, were mostly described in a list of high level criteria, ${ }^{3,48,50,52,54-59}$ with some countries including a more detailed checklist with specific aspects. ${ }^{47,49,60}$ Ontario was the sole example where criteria were presented as a set of specified questions. There were 48 questions divided in five categories: the condition, test and treatment, but also stakeholder support and experience from other jurisdictions. ${ }^{51}$ A second key difference amongst the countries was that some included criteria on the practical aspects of screening, such as the readiness of facilities to implement new conditions, and considerations on privacy. ${ }^{4,47,51,58}$ Lastly, the number of criteria per topic varied between countries. The number of criteria focussing on the condition, test, and treatment was higher in New Zealand, whereas the Dutch and UK's had more criteria addressing the practical aspects of the screening program, such as having a quality assurance program in place. $^{4,49,58}$

In addition to the number of criteria on a similar topic of screening, the content of the listed criteria also differed between countries. The UK uniquely specified that screening must be a last resort after all other options are considered, and ${ }^{58}$ included a criterion on anticipating public pressure. ${ }^{51,49,58}$ Technological developments were also included in some countries criteria, for example if the analyses could be multiplexed on the technologies already in use. ${ }^{41,52,59,61}$ One of the technological developments frequently discussed in the context of DBS is genomic technology. In contrast to most countries, Germany's, New Zealand's and Australia's policy documents lacked specification on technologies for genetic screening. ${ }^{48,49}$

Condition assessment. The use of the 2006 ACMG's quantitative system was illustrated in policy documents from the USA and Denmark. ${ }^{46,47,50}$ In this model, each criterion has categorical scoring options of either $0,50,100$, or 200. For example, the burden of disease 
can be assessed 'minimal' (score 0) to 'profound' (score 100). ${ }^{46,47}$ The Danish assessment is less technology driven than the USA's system from 2006, reflected in the selected six aspects from the ACMG's list of 16; less emphasis was placed on availability of a multiplex platform screening method and economic considerations. ${ }^{50}$ The Wilson and Jungner principles are subjective, and inherently hard to quantify. Since the RUSP in 2006, the Advisory Committee on Heritable Disorders in Newborns and Children has developed a new assessment tool based on a matrix where 'net benefit' is central. ${ }^{41}$ Most countries have not followed a purely quantitative approach, and instead summarize relevant studies combined with expert opinions. $3,4,48,49,51-53,58,60,62$ Assessment against each criterion then occurs through a consensus process informed by discussions with several stakeholders.

Level of evidence. Several policy documents acknowledge that, whereas high levels of evidence should be strived for, complete evidence for DBS will be scarce. ${ }^{3,41,51,53}$ Most countries therefore use a combination of several types of evidence, and only the UK specifies a criterion that evidence from high quality RCTs must be available. ${ }^{58}$ Australia, New Zealand, and the USA, use comparable categories to rank the level of evidence, with higher levels preferred. ${ }^{41,46,48,49}$ There are some countries where the system to assess the level of evidence is not specified, such as in the Netherlands and Germany. ${ }^{52,55}$

Recommendation. Numerous ways of formulating recommendations were represented in the policy documents, similar to the scientific literature. In the policy documents some countries did not specify categories, ${ }^{51,57,63,64}$ however, the majority did. ${ }^{3,4,41,49,52,53,58}$ Despite similarities in the recommendation categories, some differences were found between countries. Two significantly different categories can be found between the UK and the USA. The UK has a unique category that specifies when screening is not recommended, clinical practice guidelines will be developed. ${ }^{58}$ On the other hand, the outcome categories for USA have strong focus on either support screening, or recommending approaches that will enable screening in the future. ${ }^{41}$ For example, where screening is not supported, a pilot study is recommended or specific steps are provided to improve feasibility or readiness for implementation of the assessed condition in DBS. The Netherlands also advises further study when a test of proven quality is not yet available or cost-effectiveness is unclear. ${ }^{52}$

\section{DISCUSSION}

This review aimed to explore the current status of decision-making for DBS internationally, through considering the factors that influence DBS criteria and the assessment of conditions. The review highlights what is commonly experienced within the translation divide; government policy lags behind the scientific debate. Nonetheless, it is clear from both mediums that a shift in the purpose of DBS is under discussion, and evidence-based and transparent decision-making is needed to shape programs in the future.

Internationally the use of the Wilson and Jungner principles persists as a starting point for decision-making. The Wilson and Jungner principles were translated to more detailed criteria in both the scientific literature and the policy documents. However, factors influencing the resultant criteria and assessment of conditions against them differed in terms of: who benefits from screening; how evidence is assessed against each criterion; and how recommendations are made. Importantly, the criteria and their use in the assessment of conditions are responsible for shaping the programs; therefore understanding how they differ internationally provides an insight into what DBS might hold in the future.

\section{Beneficiary of screening}

Since the inception of DBS, there has been a gradual shift illustrated by several authors in the definition of beneficiary from solely the child, to also include the family. ${ }^{1,14,24,37}$ Who benefits from screening is a fundamental concept, which is linked with the purpose of the program, and heavily influences decision-making. The purpose of screening in general is to provide better health outcomes for an individual, through early detection of a disease., ${ }^{2,5,6}$ DBS has traditionally been implemented in line with this ethos, and has evolved from screening for PKU, where the sole direct beneficiary is the newborn. However, particularly in scientific literature authors highlight a shift away from newborns as the sole beneficiary. Despite this, there is no consistent advocacy towards a broader concept of beneficiary of screening. In the context of policy for DBS programs, this shift is less apparent.

At the core of the incongruity between the beneficiary of screening within the scientific literature and policies explored, are the purpose of the program and the role of governments. ${ }^{37}$ The role of government in the context of traditional DBS has been clear; to support early identification of conditions, which respond to treatment. ${ }^{37}$ Expanding the definition of beneficiary screening, to include concepts such as reproductive planning, challenges this understanding. In the context of tax-payer funded public health approaches, the appropriateness of governments to support such a concept is unclear. Further, expanding the beneficiary to include family benefit requires additional counseling services and facilities, and has wide-reaching implications that need appropriate consideration as they could potentially threaten the success of a program. Therefore, if governments support expanding the concept of beneficiary as a public health priority, they must also be in a position to implement the programs in a way that ensures quality of screening.

\section{Screening criteria}

Despite the shift away from the historical concept of beneficiary of DBS, the Wilson and Jungner principles have stood the test of time. Within almost all the documents reviewed, the Wilson and Jungner principles were the starting point for decision-making, providing high level criteria that were then adapted to more detailed criteria. These adapted criteria increase the transparency of decision-making; this is because the resultant requirements to fulfill a criterion are more straightforward and well-defined. Further, the adaptations made to the Wilson and Junger criteria tailor decision-making for DBS, to enable assessment of relevant technologies, and support ethical considerations. ${ }^{19,21-31}$ In addition to having increased level of detail, several countries also adapted the criteria to support consideration of issues relating to the implementation of the program. ${ }^{4,58}$ This enables a more complete assessment of DBS, from a system-wide perspective. It enables exploration of essential components, which in the past have been neglected in decision-making, including: quality assurance, timely follow-up and capacity of the health system to respond to a condition. ${ }^{12,20,45,65}$ This system-wide approach is in line with the modern understanding of a screening program, whereby it is necessary to consider the program as the sum of its parts, and no one component in isolation. Further, there is the risk that without this inclusive point of view a recommendation for screening could be arrived at, but not be able to be implemented. ${ }^{12,20,65,66}$

Within their decision-making criteria, countries also expressed differences in their focus on relevant technologies. As an example, New Zealand did not specifically address genomic testing, despite it being the technological drive for much debate in DBS. ${ }^{17,20,26,36,66}$ Genomic tests present a challenge for DBS worldwide, because their 
possible application poses a complex set of questions regarding ethical, legal, and societal issues. ${ }^{66}$ For example, who should be informed, what information should be given, and where this information needs to be stored. ${ }^{66}$ Through genomic testing there is also the potential to screen for a wider range of conditions, including those which are untreatable. However, this means that the need to diagnose in the newborn period is not always black and white. ${ }^{67}$ The appropriateness of screening these conditions through DBS is questionable, and is the source of much debate in the academic and policy landscapes. There is also the fear that the use of genomic tests in DBS might reduce participation when testing for untreatable conditions is started. ${ }^{52,68} \mathrm{On}$ the basis of these concerns, governments may not regard it as appropriate to offer DBS testing for untreatable conditions. However, it is argued that the introduction of genomic testing into DBS is inevitable, either through government or direct-to-consumer tests. Therefore, governments need to have decision-making processes in place to evaluate tests and protect citizens against the risks of unsound testing. ${ }^{69}$ However, in doing so, it is argued that conditions and not technologies should remain at the center of decision-making processes for DBS. ${ }^{67}$

\section{Assessment and recommendation}

Assessing conditions for DBS in a structured and transparent way against defined criteria can be challenging. ${ }^{4}$ Scientific data to assess a condition is often lacking, and a robust system with quantitative scores has been argued to be unsuitable to balance benefits and harms of screening. ${ }^{11,36}$ Therefore, most countries used a flexible system taking into account expert opinions. Although this approach leaves more room for considerations of ethical, legal, and societal issues, ${ }^{1,14}$ it also potentially makes the assessment process less transparent. The system to rank evidence is not always clear and consequently potential differences may dependent on who assesses the evidence, rather than on the evidence as such. In general, it seems the UK system has higher standards for evidence before starting screening for a condition by requesting evidence from $\mathrm{RCTs}$, which is also evident in the limited amount of conditions screened for compared with the other Western societies. Additionally, assessment seems to steer away from screening, as recommendations in the UK uniquely included a category on developing clinical guidelines instead of focussing on screening. ${ }^{58}$ Most other countries do not put RCTs forward as a feasible standard for the evidence or initiate pilot studies to gather additional evidence, reflected in the higher number of conditions screened for in those countries.

\section{Limitations and strengths}

One of the limitations of our study is that not all decision-making criteria presented in the policy documents have been used in decisionmaking for DBS programs currently in place (Table 1). This hampered an international comparison between programs that took into account the impact of decision-making on the resultant conditions included in a program. A further limitation is that only eight countries were reviewed, due to language barriers experienced by the research team. This means relevant information was possibly excluded. Regardless of the limitations, the research team was able to include countries with different program structures, and use a unique combination of scientific literature and policy documents to assess decision-making criteria. This enabled a highly structured approach resulting in key topics to guide policy development. This is timely, given that several countries are developing decision-making policies to guide program development, including in Australia and Canada. Further, as was evident in a recent review from Therrell et $a l^{8}$ a considerable number of countries worldwide are commencing DBS or expanding their programs.

\section{CONCLUSION}

There is no one decision-making solution when it comes to DBS. However, there are some clear issues that each country needs to address to guide decision-making, including: who will benefit from the program, how to ensure transparent decisions, and the role of the government. This review provides a valuable framework of issues that should be considered by governments responsible for DBS decisionmaking, as a starting point to structure the policy development in the broad context of DBS. This is especially valuable given the potential of genomic technologies to drive a push to expand programs. Further, this review highlights the need for governments to better understand the academic debate and guidance, to ensure that DBS decisionmaking frameworks are contemporary and support assessment of the current and future issues facing DBS.

\section{CONFLICT OF INTEREST}

The authors declare no conflict of interest.

\section{ACKNOWLEDGEMENTS}

MEJ acknowledges APOGEE-Net/CanGèneTest (Canada, PI Prof A Brand, PhD MD) and Haak Bastiaanse Kuneman Stichting (Netherlands, PI ME Jansen, MSc) for their financial support. The financial support facilitated a research visit to the Office of Population Health Genomics, Perth Western Australia.

1 Grosse SD, Boyle CA, Kenneson A, Khoury MJ, Wilfond BS: From public health emergency to public health service: the implications of evolving criteria for newborn screening panels. Pediatrics 2006; 117: 923-929.

2 World Health Organization. Early detection of cancer, 2015. Available from: http://who. int/cancer/detection/en/. Accessed on 3 March 2015.

3 Australian Population Health Development Principal Committee. Screening Subcommittee: Population Based Screening Framework, 2008.

4 Health Council of The Netherlands. Screening: Between Hope and Hype, 2008.

5 Elliman DAC, Dezateux C, Bedford HE: Newborn and childhood screening programmes: criteria, evidence, and current policy. Arch Dis Child 2002; 87: 6-9.

6 UK National Screening Committee. What is screening? 2015. Available from: http:// www.screening.nhs.uk/cms. php?folder $=2436$. Accessed on 29 March 2015.

7 Andermann A, Blancquaert I, Beauchamp S, Dery V: Revisiting Wilson and Jungner in the genomic age: a review of screening criteria over the past 40 years. Bull World Health Organ [online] 2008; 86: 317-319.

8 Therrell BL, Padilla CD, Loeber JG et al: Current status of newborn screening worldwide, 2015. Sem Perinat 2015; 39: 171-187.

9 Petros M: Revisiting the Wilson-Jungner criteria: how can supplemental criteria guide public health in the era of genetic screening? Genet Med 2012; 14: 129-134.

10 Pollitt RJ: Introducing new screens: Why are we all doing different things? J Inherit Metab Dis 2007; 30: 423-429.

11 Wilfond BS, Parad RB, Fost N: Balancing benefits and risks for cystic fibrosis newborn screening: implications for policy decisions. J Pediatr 2005; 147: S109-S113.

12 Moyer VA, Calonge N, Teutsch SM, Botkin JR: Expanding newborn screening: process, policy, and priorities. Hastings Cent Rep 2008; 38: 32-39.

13 Plass AMC, van EI CG, Pieters T, Cornel MC: Neonatal screening for treatable and untreatable disorders: prospective parents' opinions. Pediatrics 2010; 125 e99-e106.

14 Avard D, Vallance H, Greenberg C, Potter B: Newborn screening by tandem mass spectrometry: ethical and social issues. Can J Public Health 2007; 98: 284-286.

15 Calonge N, Green NS, Rinaldo P et al: Committee report: method for evaluating conditions nominated for population-based screening of newborns and children. Genet Med 2010; 12: 153-159.

16 Maxwell SJ, O'Leary P: Newborn bloodspot screening: setting the Australian national policy agenda. Med J Aust 2014; 200: 142-143.

17 Pollitt RJ: Newborn blood spot screening: new opportunities, old problems. J Inherit Metab Dis 2009; 32: 395-399.

18 Seymour CA, Thomason MJ, Chalmers RA et al: Newborn screening for inborn errors of metabolism: a systematic review. Health Technol Assess 1997; 1: i-iv 1-95.

19 Borte S, von Döbeln U, Hammarström L: Guidelines for newborn screening of primary immunodeficiency diseases. Curr Opin Hematol 2013; 20: 48-54.

20 Dhondt JL: Expanded newborn screening: social and ethical issues. J Inherit Metab Dis 2010; 33: S211-S217. 
21 Wilson JMG, Jungner G: Principles and Practice of Screening for Disease. World Health Organization: Geneva, 1986. Available from: http://www.who.int/bulletin/volumes/86/4/ 07-050112bp.pdf?ua $=1$.

22 Botkin JR: Assessing the new criteria for newborn screening. Health Matrix Clevel 2009; 19: 163-186.

23 Forman J, Coyle F, Levy-Fisch J, Roberts P, Terry S, Legge M: Screening criteria: the need to deal with new developments and ethical issues in newborn metabolic screening. J Commun Genet 2013; 4: 59-67.

24 Green A, Pollitt RJ: Population newborn screening for inherited metabolic disease: current UK perspectives. J Inherit Metab Dis 1999; 22: 572-579.

25 Pollitt RJ: International perspectives on newborn screening. J Inherit Metab Dis 2006; 29: 390-396.

26 Potter BK, Avard D, Wilson BJ: Newborn blood spot screening in four countries: stakeholder involvement. J Public Health Policy 2008; 29: 121-142.

27 Bonham JR: Impact of new screening technologies: should we screen and does phenotype influence this decision? J Inherit Metab Dis 2013; 36: 681-686.

28 Grosse SD, Kalman L, Khoury MJ: Evaluation of the validity and utility of genetic testing for rare diseases. Adv Exp Med Biol 2010; 686: 115-131.

29 Ross LF: Newborn screening for lysosomal storage diseases: an ethical and policy analysis. J Inherit Metab Dis 2012; 35: 627-634.

30 Feuchtbaum L, Faulkner L, Verghese S: Tandem mass spectrometry program implementation challenges for state newborn screening programs: national survey of barriers and issues. Pediatrics 2006; 117: S253-S260.

31 Ross LF: Predictive genetic testing for conditions that present in childhood. Kennedy Inst Ethics J 2002; 12: 225-244.

32 Waggoner DJ, Tan CA: Expanding newborn screening for lysosomal disorders: opportunities and challenges. Dev Disabil Res Rev 2011; 17: 9-14.

33 Ross LF, Moon MR: Ethical issues in genetic testing of children. Arch Pediatr Adolesc Med 2000; 154: 873-879.

34 Cornel MC, Rigter T, Weinreich SS et al: A framework to start the debate on neonatal screening policies in the EU: an expert opinion document. Eur J Hum Genet 2014; 22: 12-17.

35 Bunnik EM, de Jong A, Nijsingh N, de Wert GMWR: The new genetics and informed consent: differentiating choice to preserve autonomy. Bioethics 2013; 27: 348-355.

36 Bailey DBJr., Beskow LM, Davis AM, Skinner D: Changing perspectives on the benefits of newborn screening. Mental Retard Dev Disabil Res Rev 2006; 12: 270-279.

37 Bombard Y, Miller FA, Hayeems RZ, Avard D, Knoppers BM: Reconsidering reproductive benefit through newborn screening: a systematic review of guidelines on preconception, prenatal and newborn screening. Eur J Hum Genet 2010; 18: 751-760.

38 Buchbinder M, Timmermans S: Newborn screening and maternal diagnosis: rethinking family benefit. Social Sci Med 2011; 73: 1014-1018.

39 Natowicz M: Newborn screening - setting evidence-based policy for protection. N Engl J Med 2005; 353: 867-870.

40 Botkin JR, Clayton EW, Fost NC et al: Newborn screening technology: proceed with caution. Pediatrics 2006; 117: 1793-1799.

41 Kemper AR, Green NS, Calonge N et al: Decision-making process for conditions nominated to the recommended uniform screening panel: statement of the US Department of Health and Human Services Secretary's Advisory Committee on Heritable Disorders in Newborns and Children. Genet Med 2014; 16: 183-187.

42 Watson M, Mann MY, Lloyd-Puryear M, Rinaldo P, Howell RR: Newborn screening: toward a uniform screening panel and system-executive summary. Pediatrics 2006; 117: S296-S307.

43 Kemper AR, Kus CA, Ostrander RJ et al: A framework for key considerations regarding point-of-care screening of newborns. Genet Med 2012; 14: 951-954.

44 Pollitt RJ: Principles and performance: assessing the evidence. Acta Paediatr Supp/ 1999; 432: 110-114.

45 Zwahlen M, Low N, Borisch B et al: Population based screening - the difficulty of how to do more good than harm and how to achieve it. Swiss Med Wkly 2010; 140: w13061.

46 American College of Medical Genetics. Newborn Screening: Toward a Uniform Screening Panel and System, 2006.
47 Advisory Committee on Heritable Disorders in Newborns and Children. Form for Nomination of a Condition for Inclusion in the Uniform Screening Panel: Health Resources and Services Administration, U.S., 2015. Available from: http://www.hrsa. gov/advisorycommittees/mchbadvisory/heritabledisorders/nominatecondition/ nominationform.pdf.

48 Human Genetics Society of Australasia. Newborn bloodspot testing, 2011. Available from: https:/www.hgsa.org.au/documents/item/29. Accessed on 29 March 2015.

49 Ministry of Health. Newborn Metabolic Screening Programma Policy Framework, 2011. Available from: https:/www.nsu.govt.nz/system/files/page/newborn_metabolic_screening_programme policy framework june_2011.pdf.

50 Nørgaard-Pedersen B, Hougaard DM: Newborn Screening for Congenital Disorders in Routine and Research: Handbook of Children with Special Health Care Needs. Springer: New York, NY, USA, 2012, pp 259-269.

51 Potter B: Addition of conditions to DBS in Ontario, Canada, 2015. (Personal Communication).

52 Health Council of The Netherlands. Neonatal screening: new recommendations. The Hague, 2015

53 Agence d'évaluation des technologies et des modes d'intervention en santé (AETMIS): Tandem Mass Spectrometry and Neonatal Blood Screening in Quebec. Summary Report Prepared by Héla Makni, Carole St-Hilaire, Laura Robb, Kathy Larouche and Ingeborg Blancquaert (AETMIS 07-03) 2007: xviii-79 p.

54 Gemeinsamer Bundesausschuss: Bericht der Arbeitsgruppe Zuzahlung des UA Prävention zum Regelungsauftrag des par, 62 Abs. 1 Satz 3 SGB V. Berlin, 2007. Available from: https://www.g-ba.de/downloads/40-268-531/2007-11-06-Abschluss-Therapiegerecht.pdf.

55 Gemeinsamer Bundesausschuss. Kinder-Richtlinien, 2011. Available from: https:// www.g-ba.de/informationen/richtlinien/15/. Accessed on 21 March 2015.

56 Health Council of The Netherlands. Neonatale screening. The Hague, 2005.

57 Nørgaard-Pedersen B, Hougaard DM: Storage policies and use of the Danish Newborn Screening Biobank. J Inherit Metab Dis 2007; 30: 530-536.

58 UK National Screening Committee. Evidence review process, 2015. Available from: http://www.screening.nhs.uk/evidencereview. Accessed on 29 March 2015.

59 UK National Screening Committee: The UK NSC recommendation on Glutaric Aciduria Type 1, 2015. Available from: http://www.screening.nhs.uk/ga1. Accessed on 29 March 2015.

60 Blancquaert I, Beauchamp S, Andermann A: Decision Support Guide For Populationbased Genetic Screening. Québec: APOGEE-Net. 2008. Available from: http://www. cangenetest.org/en/publications.html.

61 Morrison A, Dowler J: Newborn Screening for Disorders and Abnormalities in Canada: Environmental Scan, 26 edn. Canadian Agency for Drugs and Technologies in Health: Ottawa, ON, Canada, 2011.

62 Axmann B: Addition of SCID to NBS in Germany, 2015. (Personal Communication).

63 GKV: Antrag auf Bewertung eines Screenings auf schwere angeborene Immundefekte ("SCID-Screening) bei Neugeborenen gemäB par, 135 Abs. 1 SGB V i. V. m. par. 26 SGB V. Berlin 2014. Available from: https://www.g-ba.de/downloads/40-268-3132/ 2015-02-19_135-SN_SCID-Screening_Antrag.pdf.

64 Lindner M, Gramer G, Haege G et al: Efficacy and outcome of expanded newborn screening for metabolic diseases-report of 10 years from South-West Germany. Orphanet J Rare Dis 2011; 6: 1.

65 Fischer KE, Grosse SD, Rogowski WH: The role of health technology assessment in coverage decisions on newborn screening. Int J Technol Assess Health care 2011; 27: 313-321.

66 Therrell BL: US newborn screening policy dilemmas for the twenty-first century. Mol Genet Metab 2001; 74: 64-74.

67 Howard HC, Knoppers BM, Cornel MC, Clayton EW, Sénécal K, Borry P: Whole-genome sequencing in newborn screening? A statement on the continued importance of targeted approaches in newborn screening programmes. Eur J Hum Genet 2015; 23: 1593-1600.

68 Bombard Y, Miller FA, Hayeems RZ et al: Public views on participating in newborn screening using genome sequencing. Eur J Hum Genet 2014; 22: 1248-1254.

69 Borry P, Henneman L, Lakeman P, Leo P, Cornel MC, Howard HC: Preconceptional genetic carrier testing and the commercial offer directly-to-consumers. Hum Reprod 2011; 26: 972-977. 